\title{
Skin autofluorescence in acute kidney injury
}

\author{
Aurelie Lavielle ${ }^{1}$, Sebastien Rubin², Alexandre Boyer ${ }^{3}$, Karine Moreau², Kalina Rajaobelina ${ }^{4}$, Christian Combe ${ }^{2,5}$ \\ and Vincent Rigalleau ${ }^{1,6^{*}}$
}

See related Research by De Corte et al., https://ccforum.biomedcentral.com/articles/10.1186/s13054-016-1409-z.

We were interested by the article from De Corte et al. about the poor long-term outcome after acute kidney injury (AKI) [1]. Besides initial oliguria, the three predictors for dialysis dependence were age, diabetes, and chronic kidney disease (CKD), which have previously been related to the accumulation of advanced glycation end-products (AGEs) as evaluated by skin autofluorescence (sAF). sAF is an indirect marker that has been related to the skin concentrations of fluorescent (pentosidine) and non-fluorescent AGEs (carboxy-methyl-lysine and carboxy-ethyl-lysine) in skin biopsies of hemodialized subjects [2]. Could sAF be altered in AKI?

From July 2014 to April 2015, we measured sAF with an AGE-Reader (DiagnOpticsTechnologies B.V., Groningen, Netherlands) in 35 patients admitted for AKI, staged F (RIFLE). Their results were compared to their theoretical values $((0.024 \times$ Years of age $)+0.83$ [3]) and to those of 35 patients with CKD waiting for a renal graft. All the patients gave written informed consent and the study was approved by the Comite de Protection des Personnes Sud-Ouest et Outre-Mer 3 (Bordeaux). A multivariate linear regression analysis was performed to study the relationship between sAF and the duration of renal failure and to adjust it to the age and gender of the subjects.

The patients with AKI and CKD had similar age, gender, body-mass index, and creatinine levels (Table 1). The SAF was lower in AKI than CKD, still significant $(p<0.001)$ after adjustment for age, gender, and creatinine. The sAF were higher than the theoretical values calculated from age: $2.31 \pm 0.36$ arbitrary units (AU; $p<0.001$ for both AKI and CKD). The

\footnotetext{
* Correspondence: vincent.rigalleau@chu-bordeaux.fr

${ }^{1}$ Endocrinologie-Nutrition, Université de Bordeaux, 33000 Bordeaux, France

${ }^{6}$ Endocrinologie-Nutrition, CHU de Bordeaux, Avenue Magellan, 33600

Pessac, France

Full list of author information is available at the end of the article
}

sAF was related to the duration of renal failure and was still significant $(\mathrm{B}=+0.43, p=0.02)$ after adjustment for age and gender (Fig. 1). In six patients with AKI, a second SAF measurement was performed $10 \pm$ 3 days later: the sAF increased from $2.61 \pm 0.72$ to $3.03 \pm 0.74(p<0.05)$.

Our results show that sAF is lower in AKI than in CKD and relates to the duration of renal failure, as expected. SAF is considered as a marker of metabolic memory [4], reflecting the accumulation of AGEs in the skin [2]. In our patients who could be analyzed twice, sAF increased by +0.4 AU after only 10 days, so they probably had normal sAF when their AKI started one month before. A normal, early measured sAF may therefore help to distinguish acute from chronic renal failure. The sAF was already high, and increased rapidly, in our patients with AKI. This concurs well with the quick rising plasmatic concentrations of AGEs in experimentally induced acute renal failure in rats [5]. High sAF has also been reported in patients admitted to intensive care units

Table 1 Characteristics of the subjects with acute and chronic renal failure

\begin{tabular}{llll}
\hline & $\begin{array}{l}\text { Acute kidney } \\
\text { injury }\end{array}$ & $\begin{array}{l}\text { End-stage renal } \\
\text { disease }\end{array}$ & $p$ \\
\hline $\mathrm{N}$ & 35 & 35 & \\
Age (years) & $62 \pm 15$ & $62 \pm 10$ & $\mathrm{NS}$ \\
Gender (percentage of women) & $57 \%$ & $54 \%$ & $\mathrm{NS}$ \\
Diabetes & $31 \%$ & $34 \%$ & $\mathrm{NS}$ \\
BMI (kg/m ${ }^{2}$ ) & $26.5 \pm 7.7$ & $24.7 \pm 3.8$ & $\mathrm{NS}$ \\
Serum creatinine (mg/dL) & $7.0 \pm 3.6$ & $7.1 \pm 1.7$ & $\mathrm{NS}$ \\
Duration of renal failure (days) & $34 \pm 28$ & $3275 \pm 2114$ & $<0.001$ \\
Smokers & $25 \%$ & $28 \%$ & $\mathrm{NS}$ \\
SAF (AU) & $2.97 \pm 0.72$ & $3.70 \pm 0.72$ & $<0.001$ \\
\hline
\end{tabular}




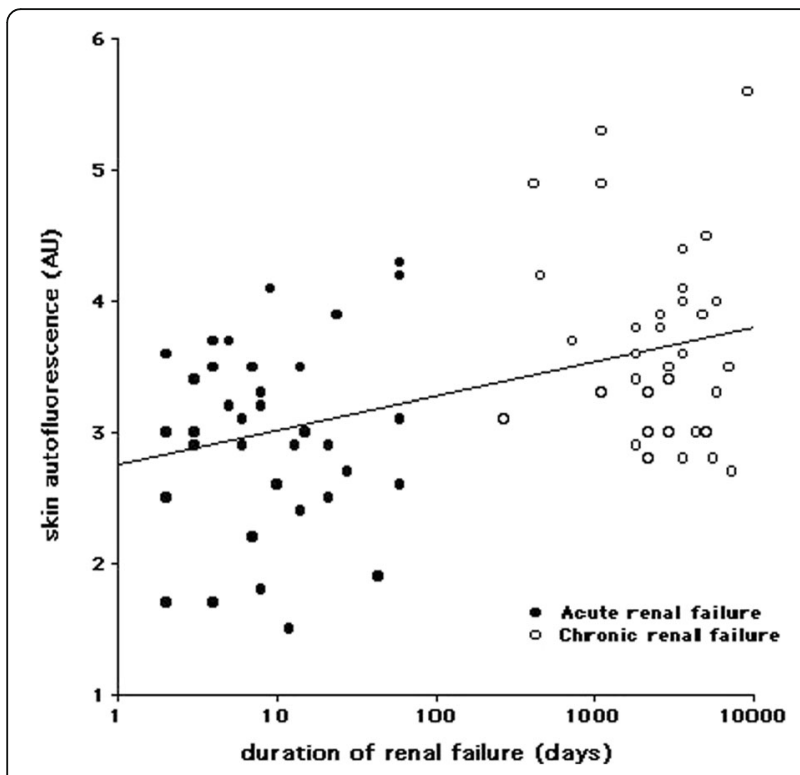

Fig. 1 Skin autofluorescence according to the duration of renal failure

[6], attributed to acute oxidative stress, which occurs in AKI. Although sAF is an indirect marker and fluorescent compounds other than AGEs accumulate in uremia, our results raise the hypothesis that the accumulation of AGEs during AKI may play a role in a later adverse outcome.

\section{Abbreviations}

AGE: Advanced glycation end product; AKI: Acute kidney injury; BMI: Body mass index; CKD: Chronic kidney disease; sAF: Skin autofluorescence

\section{Acknowledgements}

Not applicable.

\section{Funding}

No funding source.

\section{Availability of data and materials}

All data generated and/or analyzed during this study are included in this article.

\section{Authors' contributions}

AL collected data and wrote the article. SR, AB, KM, and CC contributed to the design of the study and collected data. KR collected data and performed the statistical analysis. VR conceived the study and wrote the article. All authors read and approved the final manuscript.

\section{Competing interests}

The authors declare that they have no competing interests.

\section{Consent for publication}

Not applicable.

\section{Ethics approval and consent to participate}

All the patients gave written informed consent for this study, which was approved by the Comité de Protection des Personnes Sud-Ouest et Outre-Mer III.

\section{Author details}

${ }^{1}$ Endocrinologie-Nutrition, Université de Bordeaux, 33000 Bordeaux, France. ${ }^{2}$ Néphrologie-Transplantation-Dialyse, Université de Bordeaux, 33000 Bordeaux, France. ${ }^{3}$ Réanimation médicale, Université de Bordeaux, 33000 Bordeaux, France. ${ }^{4} \mathrm{CHU}$ de Bordeaux, Bordeaux Public Health, Université de Bordeaux, 33000 Bordeaux, France. ${ }^{5}$ Unité INSERM 1026, Université de
Bordeaux, Bordeaux, France. ${ }^{6}$ Endocrinologie-Nutrition, $\mathrm{CHU}$ de Bordeaux, Avenue Magellan, 33600 Pessac, France.

Published online: 09 February 2017

\section{References}

1. De Corte W, Dhondt A, Vanholder R, De Waele J, Decruyenaere J, Sergoyne $\mathrm{V}$, et al. Long-term outcome in ICU patients with acute kidney injury treated with renal replacement therapy: a prospective cohort study. Crit Care. 2016;20:256.

2. Meerwaldt RR, Hartog JWL, Graaff R, Huisman RJ, Links TP, den Hollander $\mathrm{RC}$, et al. Skin autofluorescence, a measure of cumulative metabolic stress and advanced glycation end products, predicts mortality in hemodialysis patients. J Am Soc Nephrol. 2005;16:3687-93.

3. Koetsier M, Lutgers HL, de Jonge C, Links TP, Smit AJ, Graaff R. Reference values of skin autofluorescence. Diabetes Technol Ther. 2010;12:399-403

4. Rajaobelina K, Cougnard-Grégoire A, Delcourt C, Gin H, Barberger-Gateau P, Rigalleau V. Autofluorescence of skin advanced glycation end products: marker of metabolic memory in the elderly population. J Gerontol A Biol Sci Med Sci. 2015;70:841-6.

5. Sebekova K, Blazicek P, Syrova D, Krivosikova Z, Spustova V, Heidland A, et al. Circulating advanced glycation end product levels in rats rapidly increase with acute renal failure. Kidney Int Suppl. 2001;78:S58-62.

6. Greven WL, Smit JM, Rommes JH, Spronk PE. Accumulation of advanced glycation end (AGEs) products in intensive care patients: an observational, prospective study. BMC Clin Pathol. 2010;10:4. 